\title{
Modelling and Experimental Validation of a Novel Co-Axial Spiral Borehole Heat Exchanger
}

\section{Antonio Cazorla-Marín Roon Hylkema}

\author{
Carla Montagud \\ José Miguel Corberán
}

\author{
Henk Witte
}

\begin{abstract}
In order to optimize the operation of a ground source heat pump (GSHP) system, the development of dynamic models that integrate all the system components is a key factor. Particularly, the modelling of the ground source beat exchanger and its coupling to the heat pump operation becomes important.

Usually, this kind of systems present an on/off operation, which makes it necessary to have an accurate prediction of both the short and long thermal response of the borehole heat exchanger (BHE). In this context, the novel B2G dynamic model was developed and experimentally validated in previous works for a single U-loop BHE.

This work presents the adaptation and experimental validation of the B2G dynamic model to a novel co-axial spiral BHE configuration designed in the framework of a HORIZON 2020 European Project, GEOT€CH (Geothermal Technology for €conomic Cooling and Heating).
\end{abstract}

The results show that the B2G approach applied to this specific configuration produces a model that can accurately predict the behavior of the BHE.

\section{INTRODUCTION}

During the last years, Ground Source Heat Pump (GSHP) systems have proven to be one of the most efficient systems for heating and cooling in buildings (Luo, et al. 2016), achieving a significant reduction of the energy consumption when compared to conventional heating and cooling systems. For example, in comparison with conventional air-to-water heat pumps, GSHP systems can provide energy savings around $40 \%$ of primary energy in the European Mediterranean coast (Urchueguía, et al. 2008).

In order to obtain an efficiency as high as possible, it is important to optimize not only the design of the components but also the integrated system's operation. For this purpose, a dynamic model of the whole system is a very useful tool, since it allows a detailed prediction of the behavior of the system during its operation. In GSHP systems, the most important component, and also the most expensive, is the Borehole Heat Exchanger (BHE). An accurate dynamic model of this component can greatly help in the prediction and overall optimization of the system behavior, especially in an ON/OFF operation GSHP system. Furthermore, an optimized design of the GSHE is key in order to obtain a good energy efficiency of the system at a reasonable cost. Providing not only energy savings, but also a higher return on investment when used instead of a conventional system. For this reason, the GSHE should not be under- 
sized (low cost but lower efficiency) nor over-sized (higher efficiency but high cost).

In this context, several GSHE models have been developed in order to reproduce the thermal behavior of different BHE configurations (a complete review is reported by Yang, et al. 2010). Some of them are focused on the prediction of the long-term response of the surrounding ground and other models able to predict the BHE short term behavior of a single heat exchanger with high accuracy are usually based on FEM technique, or employ very large and refined thermal grids and implicit numerical schemes, so requiring very long computational times and making them less attractive for integrated system simulations. In this context, the B2G dynamic model was developed for a single U-tube BHE configuration. The B2G model is based on the thermal network approach (5C6R), combined with a vertical discretization of the borehole. The model attempts to find the simplest thermal grid for the borehole and nearby surrounding ground, which is able to retain the accuracy for the instantaneous heat transfer along one day with low computation cost (less than 6 seconds for a 24 hour simulation on a modern PC). This model has been implemented in TRNSYS environment (De Rosa, et al. 2015) and validated against experimental data (Ruiz-Calvo, et al. 2015). It is able to predict the short-term behavior of the BHE with high accuracy.

The B2G dynamic model was developed for a single U-tube BHE, but this configuration is not the most efficient from the point of view of the heat transfer due to the interference between the downward pipe and the upward pipe. Especially when the mass flow rate is low and Reynolds numbers drop below 2300 (laminar flow conditons) the thermal resistance of the borehole heat exchanger can be dramatically increased, resulting in a reduced thermal efficiency.

To improve efficiency at low Reynolds numbers and, at the same time, reduce the thermal losses between downand upflowing channels, a new coaxial heat exchanger, with an insulated inner pipe and a spiral fluid flow path in the outer pipe, has been developed by Geothex BV (http://geothex.nl). This novel heat exchanger will be further developed and optimized within the framework of the GEOT€CH European Horizon 2020 project, Geothermal Technology for $€$ conomic Cooling and Heating. Preliminary investigations showed a significant increase of efficiency compared to conventional heat exchanger designs (50\% lower thermal resistance compared to a U-tube heat exchanger with turbulent flow and over $75 \%$ lower thermal resistance compared with a U-tube heat exchanger at laminar flow or compared with a conventional concentric heat exchanger), especially at low Reynolds numbers (Witte 2012).

The B2G model has been adapted to the innovative co-axial configuration with spiral flow path as a part of the GEOT€CH project and validated against experimental data from a Thermal Response Test (TRT) carried out in a real BHE located at the Geothex BV facilities in Houten, Netherlands (Witte, et al 2002).

In this work, the B2G model is described as well as the adaptation to the novel co-axial BHE with spiral flow path. The description of the BHE is presented as well as the TRT carried out. The model has been validated against the experimental data from this TRT, and predicts the behavior of the BHE with high accuracy (root mean square error (RMSE) lower than $0.1 \mathrm{~K}$ ).

\section{B2G MODEL}

In order to accurately model the dynamic behavior of a single $\mathrm{U}$-tube BHE, the B2G model was developed and presented previously in (Ruiz-Calvo, et al. 2015) and (De Rosa, et al. 2015). This model is able to reproduce with high accuracy the short-term behavior of the BHE in terms of water temperature throughout the pipe. To reduce computational time, only the portion of surrounding ground directly affected by the considered heat injection/extraction period is taken into account (normally around 10-15 hours for a GSHP system that switches off during the night).

The BHE is discretized vertically in $n$ divisions and, in each borehole depth, a $2 \mathrm{D}$ thermal network represents the radial heat transfer. The thermal network consists of 5 nodes connected by 6 thermal resistances. Each node represents one of the parts of the BHE: the downward and upward fluid inside the pipe, the borehole backfilling and the surrounding ground. Each node also includes a thermal capacitance, taking into account the thermal inertia of each part.

Although the vertical conduction is neglected, for the fluid nodes, the advection in vertical direction has been

taken into account in the transient energy balance equations. The entire model consists of a 5C6R-n model (5 thermal 
capacitances and 6 thermal resistances in each $Z$-depth and $n$ vertical divisions of the BHE), this is a system of ordinary differential equations that can be solved using standard numerical procedures, as described in (Ruiz-Calvo, et al. 2015).

The B2G model has been validated against experimental data from a real borehole located in Stockholm, Sweden, using different step-tests (Ruiz-Calvo, et al. 2015). Furthermore, it has been validated against experimental data from a real borehole located at Universitat Politècnica de València, Spain, under different operation conditions: a step-test and the normal ON/OFF operation of the GSHP system in which the borehole is installed (De Rosa, et al. 2015).

\section{ADAPTATION OF THE B2G MODEL TO THE NEW CONFIGURATION}

\section{Model Description}

The B2G dynamic model has been adapted to the new co-axial configuration with spiral flow path. For this purpose, the thermal network has been modified, taking into account the different parts of the new BHE configuration: the fluid in the inner pipe is represented by $T_{i}$, the fluid in the outer pipe is represented by $T_{o}$, the grout is represented by $T_{b}$ and the surrounding ground is represented by two nodes, $T_{g 1}$ and $T_{g 2}$. The reason for considering two ground nodes, instead of only one, is to obtain a higher accuracy both on the short-term and the mid-term behavior. The first ground node is located in order to consider a short period of heat injection/extraction (for example 1 hour), while the second considers a larger period of injection/extraction of time (for example 15 hours). These ground nodes' positions are represented by the ground penetration diameters $\left(D_{g p 1}\right.$ and $D_{g p 2}$, respectively) and are calculated according to the equation for a region bounded internally by a circular cylinder and constant heat flux on its surface (Carslaw and Jaeger 1959). It takes into account the thermal properties of the ground and the injection/extraction period of time. Figure 1(a) shows the thermal network on the borehole layout.

The BHE is discretized vertically from the top to the bottom in $n 2 \mathrm{D}$ thermal networks, each thermal network has five nodes with their respective thermal capacitances and four thermal resistances. Furthermore, the vertical conduction along the borehole depth is considered on the grout and the ground. So, each thermal network is connected to its adjacent thermal networks via vertical thermal resistances as it is shown in Figure 1(b).
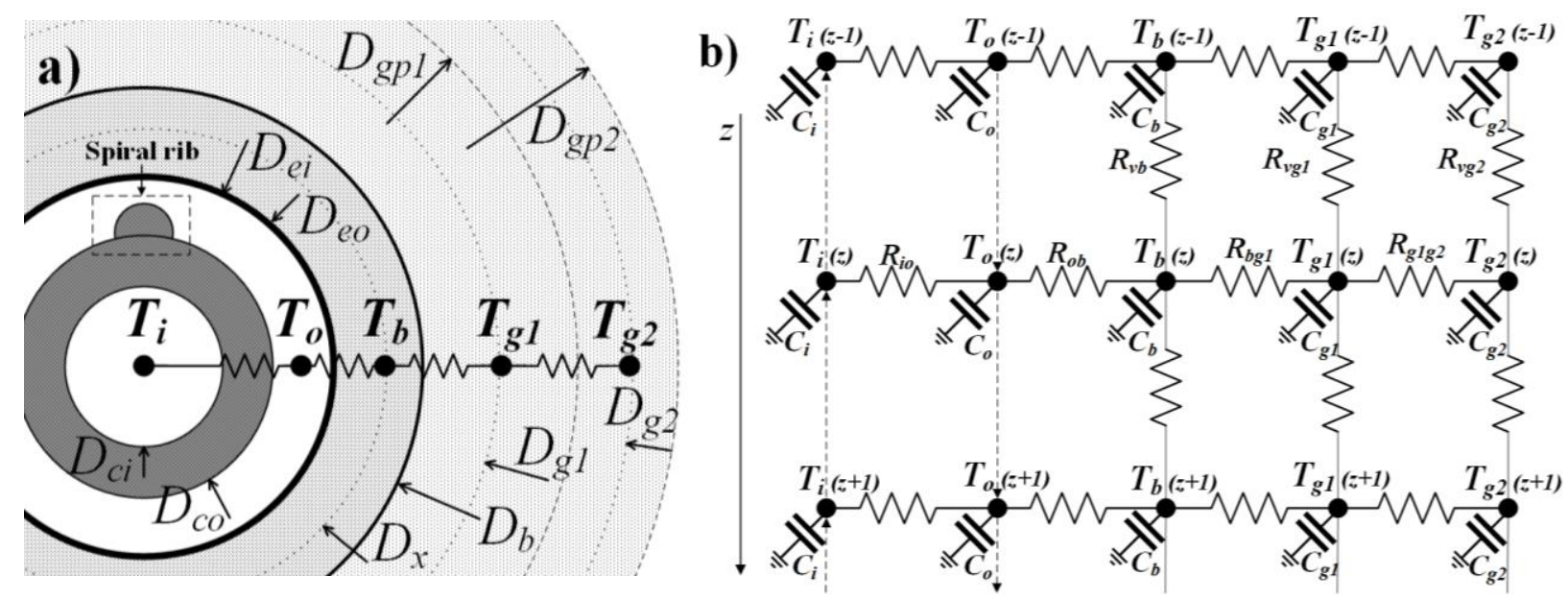

Figure 1 Thermal network of the coaxial configuration model: a) borehole layout; b) vertical discretization.

The energy balance equations for the different nodes are described in the equations (1)-(5), the vertical advection in the fluid nodes is taken into account and the vertical conduction between grout and ground nodes. The velocity of 
the fluid in the inner pipe and the outer pipe is represented by $v_{i}$ and $v_{o}$, respectively.

$$
\begin{gathered}
\frac{\partial T_{i}(z)}{\partial t}=v_{i} \frac{\partial T_{i}(z)}{\partial z}-\frac{1}{C_{i}}\left(\frac{T_{i}(z)-T_{o}(z)}{R_{i o}}\right) \\
\frac{\partial T_{o}(z)}{\partial t}=-v_{o} \frac{\partial T_{o}(z)}{\partial z}-\frac{1}{C_{o}}\left(\frac{T_{o}(z)-T_{i}(z)}{R_{i o}}+\frac{T_{o}(z)-T_{b}(z)}{R_{o b}}\right) \\
C_{b} \frac{\partial T_{b}(z)}{\partial t}=\frac{T_{o}(z)-T_{b}(z)}{R_{o b}}+\frac{T_{g 1}(z)-T_{b}(z)}{R_{b g 1}}+\frac{T_{b}(z-1)-T_{b}(z)}{R_{v b}}+\frac{T_{b}(z+1)-T_{b}(z)}{R_{v b}} \\
C_{g 1} \frac{\partial T_{g 1}(z)}{\partial t}=\frac{T_{b}(z)-T_{g 1}(z)}{R_{b g 1}}+\frac{T_{g 2}(z)-T_{g 1}(z)}{R_{g 1 g 2}}+\frac{T_{g 1}(z-1)-T_{g 1}(z)}{R_{v g 1}}+\frac{T_{g 1}(z+1)-T_{g 1}(z)}{R_{v g 1}} \\
C_{g 2} \frac{\partial T_{g 2}(z)}{\partial t}=\frac{T_{g 1}(z)-T_{g 2}(z)}{R_{g 1 g 2}}+\frac{T_{g 2}(z-1)-T_{g 2}(z)}{R_{v g 2}}+\frac{T_{g 2}(z+1)-T_{g 2}(z)}{R_{v g 2}}
\end{gathered}
$$

Regarding the spiral flow path inside the outer pipe, an equivalent section and an equivalent hydraulic diameter in the calculation of the hydraulic and thermodynamic properties are considered. The numerical resolution of the entire model is analogous to the resolution for the single $\mathrm{U}$-tube model.

\section{Parameter Calculation}

The main parameters of the model are the thermal capacitances and the thermal resistances, which can be determined taking into account the thermo-physical properties and the geometrical characteristics of the borehole, similarly to the single U-tube B2G model (Ruiz-Calvo, et al. 2015).

Thermal Capacitances $(C)$ are calculated with the volumetric thermal capacitance $(c)$ and the volume of the zone in each vertical division $(d z)$. The ground and grout capacitances are calculated according to the equations in (6), where $D_{b}$ represents the borehole diameter and $D_{e o}$ represents the external diameter of the outer pipe.

$$
C_{g 1}=\frac{\pi}{4}\left(D_{g p 1}^{2}-D_{b}^{2}\right) c_{g 1} d z \quad ; \quad C_{g 2}=\frac{\pi}{4}\left(D_{g p 2}^{2}-D_{g p 1}^{2}\right) c_{g 2} d z \quad ; \quad C_{b}=\frac{\pi}{4}\left(D_{b}^{2}-D_{e o}^{2}\right) c_{b} d z
$$

The thermal capacitance of the fluid nodes is calculated taking into account the heat capacity $\left(C_{p}\right)$, the fluid density $(\rho)$ and the volume, according to the equation (7), where $D_{c i}$ represents the inner diameter of the inner pipe, $D_{e i}$ represents the inner diameter of the outer pipe and $D_{c o}$ represents the outer diameter of the inner pipe.

$$
C_{i}=\frac{\pi}{4} D_{c i}^{2} C_{p, i} \rho_{i} d z \quad ; \quad C_{o}=\frac{\pi}{4}\left(D_{e i}^{2}-D_{c o}^{2}\right) C_{p, o} \rho_{o} d z
$$

Thermal resistances are calculated as an addition of conductive and convective cylindrical thermal resistances. The nodes are located at an equivalent diameter in order to calculate the conductive resistance. The equivalent diameter is calculated as a mean diameter of the zone according to the equation (8), where $D_{x}$ is the borehole node diameter, $D_{g 1}$ corresponds to the short-term node diameter and $D_{g 2}$ corresponds to the mid-term node diameter. 


$$
D_{x}=\frac{D_{b}+D_{e o}}{2} ; \quad D_{g 1}=\frac{D_{g p 1}+D_{b}}{2} ; \quad D_{g 2}=\frac{D_{g p 2}+D_{g p 1}}{2}
$$

The convective thermal resistance is calculated using the mean convective heat transfer coefficient $(h)$ of the fluid in the inner pipe $\left(h_{i}\right)$ and in the outer pipe $\left(h_{o}\right)$ according to the equation (9). The Nusselt number $(N u)$ is calculated depending on the flow regime (e.g. (Gnielinski 2010)), and $k$ represents the thermal conductivity of the fluid.

$$
h=\frac{N u k}{D}
$$

For the inner pipe, the internal diameter is considered; for the outer pipe, it is considered an equivalent hydraulic diameter, taking into account the spiral flow path.

On the other hand, the conductive thermal resistances are calculated taking into account the conductivities of the inner pipe $\left(k_{i p}\right)$, the outer pipe $\left(k_{o p}\right)$, the grout $\left(k_{b}\right)$ and the ground $\left(k_{g}\right)$. The total thermal resistances between the different nodes in the thermal network are described in the equations (10)-(13).

$$
\begin{gathered}
R_{i o}=\frac{1}{\pi D_{c i} d z h_{i}}+\frac{\ln \left(D_{c o} / D_{c i}\right)}{2 \pi k_{i p} d z}+\frac{1}{\pi D_{c o} d z h_{o}} \\
R_{o b}=\frac{1}{\pi D_{e i} d z h_{o}}+\frac{\ln \left(D_{e o} / D_{e i}\right)}{2 \pi k_{o p} d z}+\frac{\ln \left(D_{x} / D_{e o}\right)}{2 \pi k_{b} d z} \\
R_{b g 1}=\frac{\ln \left(D_{b} / D_{x}\right)}{2 \pi k_{b} d z}+\frac{\ln \left(D_{g 1} / D_{b}\right)}{2 \pi k_{g} d z} \\
R_{g 1 g 2}=\frac{\ln \left(D_{g 2} / D_{g 1}\right)}{2 \pi k_{g} d z}
\end{gathered}
$$

Regarding the vertical thermal resistances between nodes of adjacent thermal networks, they are calculated according to the equations in (14), depending on the thermal conductivity, the vertical distance between nodes $(d z)$ and the annulus surface. It is considered the same thermal conductivity for the vertical and radial direction.

$$
R_{v b}=\frac{d z}{\frac{\pi}{4} \cdot\left(D_{b}^{2}-D_{e o}^{2}\right) \cdot k_{b}} \quad ; \quad R_{v g 1}=\frac{d z}{\frac{\pi}{4} \cdot\left(D_{g p 1}^{2}-D_{b}^{2}\right) \cdot k_{g}} \quad ; \quad R_{v g 2}=\frac{d z}{\frac{\pi}{4} \cdot\left(D_{g p 2}^{2}-D_{g p 1}^{2}\right) \cdot k_{g}}
$$

\section{EXPERIMENTAL VALIDATION}

\section{Geothex $^{\circledR}$ Borehole Heat Exchanger}

The main innovations of the Geothex ${ }^{\circledR}$ heat exchanger consist of an insulated inner pipe to minimize heat loss between the inner and outer flow channel and spiralling vanes in the annular space to enhance heat transfer, especially at low Reynolds numbers. As can be seen in Figures 1(a) and 2, the edge of the vane and the inner wall of the outer pipe are not in full contact. In fact, there is a gap of about $3.25 \mathrm{~mm}$ on average. Although the vanes will touch the inner wall of the outer pipe at different places, the spiral flow path is not completely closed. The reason for the existence of this gap is twofold. First of all, manufacturing tolerances of the special inner pipe material are not as high as in conventional extruded pipes. Secondly, and perhaps more importantly, if the fit would be very tight it would be very difficult to insert 
the inner pipe in the outer pipe due to friction, especially when the length of the heat exchanger increases.

Fluid flowing through the gap may generate a local higher turbulence and hence an increase in the heat transfer coefficient from the fluid in the outer pipe to the grout/ground. In the following two scenarios, one without gap flow and one with gap flow, will be considered.

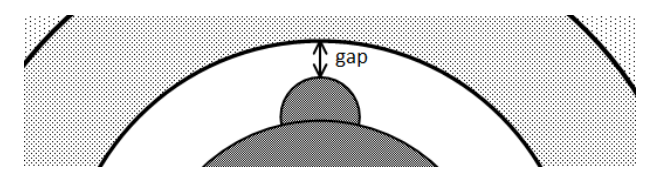

Figure 2 Gap between the spiral rib and the outer pipe wall

\section{Validation of the model}

The new model has been implemented as a TRNSYS type where the geometrical characteristics and the thermal properties are set as parameters. The temperature and the mass flow rate of the inlet fluid are introduced as inputs and the model calculates the outlet temperature and the heat transferred to the surrounding ground.

In order to validate the model, data from a TRT carried out using the BHE described in the previous section is used. The inlet temperature and mass flow rate are introduced, and the calculated outlet temperature is compared to experimental measurements. The temperature measurements during the TRT were carried out with two PT100 sensors, calibrated in situ with a standard deviation of the temperature measured of $0.028 \mathrm{~K}$. The error of the flow measurement is less than $0.2 \%$ of the flow rate. A complete description of the experimental setup and error analysis is given in Witte (2012). The difference between the simulated and the experimental outlet temperature is analyzed and the root mean square error (RMSE) is calculated. The amount of heat transferred to the ground is also compared. For the simulation, a test length of 15 hours is used (which is a common daily operation schedule for ON/OFF GSHP systems that switch off at night) and the TRT data is introduced in intervals of 1 minute. Regarding the penetration diameters, the shortterm ground node, $D_{g 1}$ is placed according to a heat extraction time of 1 hour; and the mid-term ground node, $D_{g 2}$, according to 15 hours of heat extraction. This means a penetration diameter $D_{g p 1}=0.3 \mathrm{~m}$ and $D_{g p 2}=0.7 \mathrm{~m}$ for the type of soil considered according to the equation for a region bounded internally by a circular cylinder and constant heat flux in its surface presented by Carslaw and Jaeger (1959). Independency from the parameter $D_{g p 1}$ was checked and it was concluded that for the short term behavior of the water along the BHE, the higher the penetration depth for the first ground node $D_{g p 1}$, the higher the RMSE. So, for the TRT analyzed in this work, $D_{g p 2}$ should be determined for the total injection period, and $D_{g p 1}$ should be set to injection periods lower than or equal to 1 hour. The number of vertical divisions adopted is 150 .

\section{Table 1. Main parameters of the model}

\begin{tabular}{cccc}
\hline Thermophysical properties & \multicolumn{3}{c}{ Geometrical characteristics } \\
\hline \hline Inner pipe conductivity & $0.20 \mathrm{~W} / \mathrm{m} \cdot \mathrm{K}$ & Length & $44.43 \mathrm{~m}$ \\
Outer pipe conductivity & $0.42 \mathrm{~W} / \mathrm{m} \cdot \mathrm{K}$ & Borehole diameter & $0.088 \mathrm{~m}$ \\
Ground thermal conductivity & $2.13 \mathrm{~W} / \mathrm{m} \cdot \mathrm{K}$ & Inner diameter of the inner pipe & $0.0285 \mathrm{~m}$ \\
Grout thermal conductivity & $1.56 \mathrm{~W} / \mathrm{m} \cdot \mathrm{K}$ & Outer diameter of the inner pipe & $0.0445 \mathrm{~m}$ \\
Ground volumetric thermal capacitance & $2410 \mathrm{~kJ} / \mathrm{m}^{3} \cdot \mathrm{K}$ & Inner diameter of the outer pipe & $0.057 \mathrm{~m}$ \\
Grout volumetric thermal capacitance & $3500 \mathrm{~kJ} / \mathrm{m}^{3} \cdot \mathrm{K}$ & Outer diameter of the outer pipe & $0.063 \mathrm{~m}$ \\
Percentage of propylene-glycol in the fluid & $20 \%(\mathrm{vol})$. & Angle of the spiral rib & $85.7^{\circ}$ \\
\hline
\end{tabular}

A sensitivity analysis was carried out for the grout conductivity and it was concluded that assuming a $\pm 25 \%$ 
uncertainty in the determination of the grout conductivity could produce up to a $70 \%$ increase in the RMSE $(\mathrm{RMSE}=0.049+0.034 \mathrm{~K})$. Regarding the spiral flow along the outer pipe of the BHE, two scenarios have been considered: a) all the fluid is following the spiral path along the outer pipe; b) there exists a part of the fluid that flows through the gap between the rib and the outer pipe wall, this phenomenon generates a higher turbulence and hence, the convective heat transfer is increased. In order to account for this phenomenon in the model, an enhancement factor in the mean convective heat transfer coefficient from the fluid along the outer pipe to the grout is defined. The heat transfer coefficient from the fluid to the inner pipe is not modified. The enhancement factor has been chosen to accurately fit the simulated results with the experimental data. In this case, the value is 1.5 (the convective heat transfer coefficient is increased by $50 \%$ ).

\section{RESULTS}

For the two cases considered (with and without gapflow), if the enhancement factor is set to 1, no gapflow is assumed; and if it is set to a value of 1.5, then enhanced heat transfer due to gapflow is assumed. In Figure 3 the calculated and experimentally measured BHE outlet temperature as well as the difference between the calculated and the measured outlet temperatures are depicted for both cases. It can be seen that, in both cases the model reproduces the measured values accurately, presenting the smallest error in the second case (Figure 3b) with enhanced heat transfer. The RMSE in case a) is $0.095 \mathrm{~K}$ and in case b), it is $0.049 \mathrm{~K}$. The highest temperature difference is $0.308 \mathrm{~K}$ in case a) and $0.212 \mathrm{~K}$ in case $\mathrm{b}$ ), and it takes place during the first half hour of the TRT.
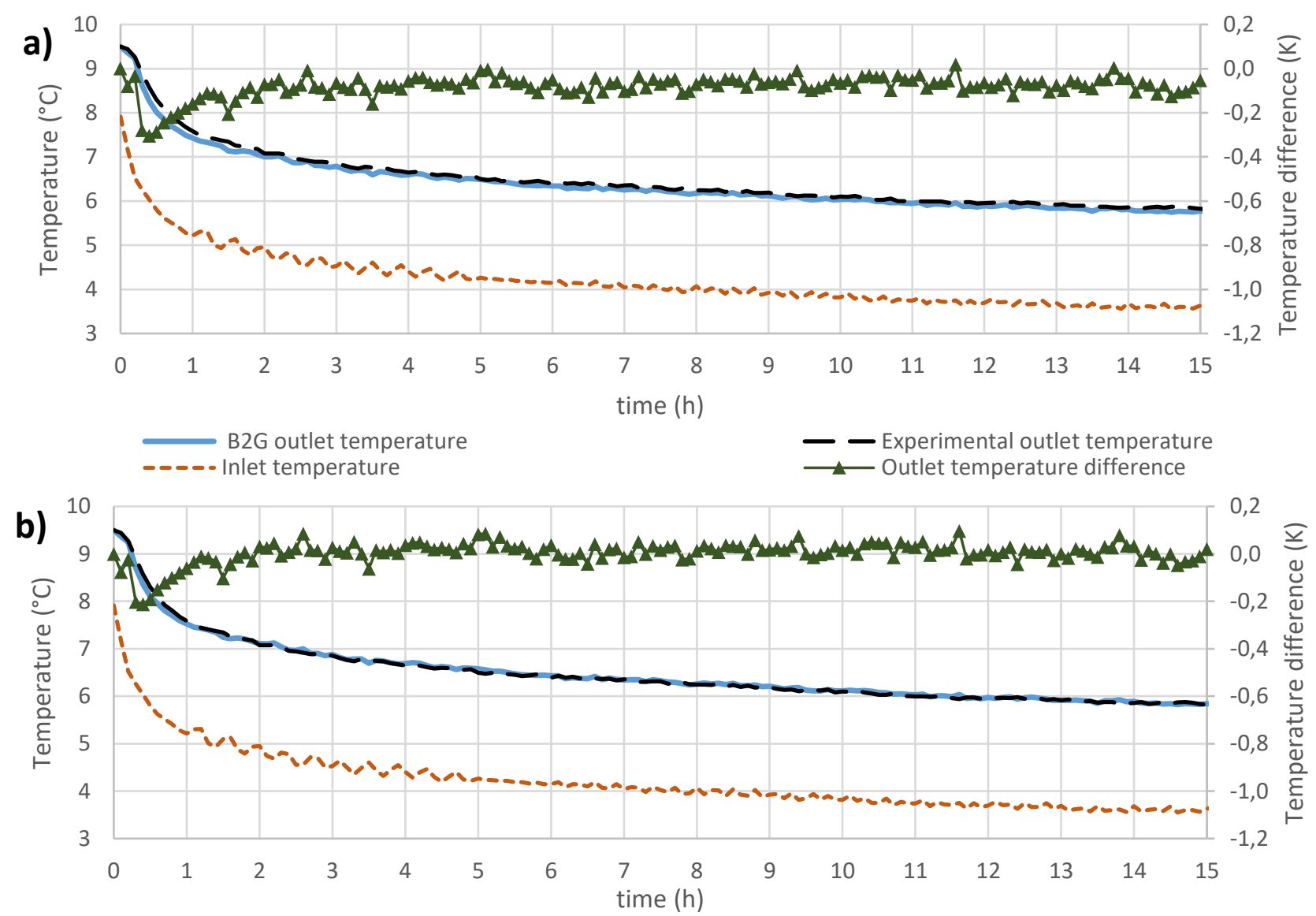

Figure 3 Comparison between the experimental outlet temperature and the calculated by the B2G model. a) fluid following the spiral path, b) Part of the fluid through the gap, enhancement factor $=1.5$. 
The heat transferred to the ground and the deviations between the experimental and simulation results are summarized in Table 2 for both cases.

Table 2. Heat transferred to the ground during the TRT

\begin{tabular}{c||cccc}
\hline Experimental & B2G model. Case a) & Percentage difference & B2G model. Case b) & Percentage difference \\
\hline \hline $43022.6 \mathrm{~kJ}$ & $41487.7 \mathrm{~kJ}$ & $-3.57 \%$ & $43097.2 \mathrm{~kJ}$ & $0.17 \%$ \\
\hline
\end{tabular}

Other important parameters of the model are shown in Table 3. The mass flow rate corresponds to the mean value introduced in the model from the experimental data; the other parameters are calculated by the model.

Table 3. Other parameters (mean values during the TRT)

\begin{tabular}{cccc}
\hline \multicolumn{2}{c}{ Hydraulic parameters } & \multicolumn{2}{c}{ Convective heat transfer coefficient } \\
\hline \hline Volumetric flow rate & $0.307 \pm 0.018\left(\mathrm{~m}^{3} / \mathrm{hr}\right)$ & Inner pipe & $79 \mathrm{~W} /\left(\mathrm{m}^{2} \cdot \mathrm{K}\right)$ \\
Reynolds number (inner pipe) & 1240 & Outer pipe (case a) & $149 \mathrm{~W} /\left(\mathrm{m}^{2} \cdot \mathrm{K}\right)$ \\
Reynolds number (outer pipe) & 321 & Outer pipe (case b) & $224 \mathrm{~W} /\left(\mathrm{m}^{2} \cdot \mathrm{K}\right)$ \\
\hline
\end{tabular}

\section{CONCLUSION}

The B2G dynamic model has proven to be an accurate model for the prediction of the short term behavior of a single U-tube BHE. In this paper it is shown how it can be adapted to a novel co-axial configuration with spiral flow path. The adapted model has been validated against experimental data from a TRT carried out at the Geothex BV facilities. In order to validate the model, two scenarios have been studied: the first one considers that all the fluid follows the spiral path along the outer pipe, the second one considers that part of the fluid flows through the gap between the rib and the pipe wall, generating a higher turbulence and hence, enhancing the convective heat transfer. In order to take into account this phenomenon, the convective heat transfer coefficient between the fluid along the outer pipe and the grout has been experimentally fitted and an enhancement factor of 1.5 in the heat transfer coefficient was obtained ( $50 \%$ better heat transfer).Both cases generate accurate results, with a RMSE lower than $0.1 \mathrm{~K}$ (a typical tolerance for the temperature sensors), although the precision of the second case (enhancement factor=1.5) is higher (RMSE $<0.05$ $\mathrm{K})$. To summarize, the B2G dynamic model adapted to the new co-axial configuration is able to predict the short term behavior of the new coaxial BHE with high accuracy, especially when it is considered that there exists an increase in the convective heat transfer due to the fact that a small part of the fluid along the outer pipe flows through the gap.

\section{ACKNOWLEDGMENTS}

The present work has been supported by the European Community Horizon 2020 Program for European Research and Technological Development (2014-2020) inside the framework of the project 656889 - GEOTeCH (Geothermal Technology for Economic Cooling and Heating) and by the Generalitat Valenciana inside the program "Ayudas para la contratación de personal investigador en formación de carácter predoctoral (ACIF/2016/131)". 


\section{REFERENCES}

Carslaw, H. S. and Jaeger, J. C. 1959. Conduction of heat in solids, New York, USA: Second ed. Oxford University Press.

European Commision. 2015. Geothermal Technology for €conomic Cooling and Heating (H2020-LCE-2014-2, GEOTeCH656889). Available online at: http://www.geotech-project.eu/.

Gnielinski, V. 2010. G1 Heat Transfer in Pipe Flow. In VDI-Gesellschaft Verfahrenstechnik und Chemieingenieurwesen VDI Heat Atlas. Düsseldorf: Second Edi. Springer-Verlag Berlin Heidelberg.

Luo, J., Rohn, J., Xiang, W., Bertermann, D. and Blum, P. 2016. A review of ground investigations for ground source heat pump (GSHP) systems. Energy and Buildings 117: 160-175.

De Rosa, M., Ruiz-Calvo, F., Corberán, J. M., Montagud, C. and Tagliafico, L. A. 2015. A novel TRNSYS type for short-term borehole heat exchanger simulation: B2G model. Energy Conversion and Management. 100: 347-357.

Ruiz-Calvo, F., De Rosa, M., Acuña, J., Corberán, J. M. and Montagud, C. 2015. Experimental validation of a short-term Boreholeto-Ground (B2G) dynamic model. Applied Energy 140: 210-223.

Urchueguía, J. F., Zacarés, M., Corberán, J. M., Montero, Á., Martos, J. and Witte, H. 2008. Comparison between the energy performance of a ground coupled water to water heat pump system and an air to water heat pump system for heating and cooling in typical conditions of the European Mediterranean coast. Energy Conversion and Management 49: 2917-2923.

Witte, H.J.L., Gelder, A.J, van and Spitler, J.D. 2002. In-situ measurement of ground thermal conductivity: The Dutch perspective. ASHRAE Transactions 108 (1): 263-272.

Witte, H.J.L. 2012. The GEOTHEX geothermal heat exchanger, characterisation of a novel high efficiency heat exchanger design. The 12th International conference on Energy Storage (Innostock 2012). Lleida, Spain. May 16-19.

Yang, H., Cui, P. and Fang, Z. 2010. Vertical-borebole ground-coupled heat pumps: a review of models and systems. Applied Energy 87: $16-27$. 